\title{
Not the Same Old Song and Dance: Viewing Racial Socialization Through a Family Systems Lens to Resist Racial Trauma
}

\author{
Shawn C. T. Jones ${ }^{1} \cdot$ Riana Elyse Anderson ${ }^{2} \cdot$ Howard C. Stevenson ${ }^{3}$
}

Accepted: 14 September 2021 / Published online: 24 September 2021

(c) Springer Nature Switzerland AG 2021

\begin{abstract}
Racial socialization has been a mainstay within the psychological literature for the past four decades, touted primarily as a protective factor buffering the negative effects of racism. How effective this factor is in preventing behavioral and emotional trauma and promoting resilience for Black and Brown families remains to be studied. While the literature has focused on family communication between parent and child, little attention has been paid to familial dynamics inherent within racial socialization processes. This paper seeks to advance the conversation of racial socialization as The Talk toward one that holds more promise toward the goal of resilience in the face of systemic racism. To do so, we offer a reframe of The Dance, drawing upon key aspects from the family- and multisystem-focused literatures (e.g., synergy, homeostasis, feedback, metacommunication) to expand and justify the utility, complexity, and efficacy of racial socialization among Black and Brown families as a resilient response to historical and contemporary systemic racism in American society. We include methodological and applied recommendations to promote resilience, resistance, and ultimately healing in the face of racial adversity and trauma.
\end{abstract}

Keywords Racial socialization $\cdot$ Racism $\cdot$ Racial trauma $\cdot$ Family systems $\cdot$ BIPOC

The brutal and highly visible murder of George Floyd by Derek Chauvin sparked a racial revolution during the summer of 2020. The oddity of this racist act during a global pandemic left many sheltered people anxiously scouring for news differently than before the pandemic. Among these news watchers were families confused about how to raise resilient children in the face of such brutality. Although some families had practice explaining racism to their children beyond general youth-related concerns (Anderson et al., 2019a), others were forced for the first time to address the "issue" of race and police brutality. This was evident by the explosion of media around these very conversations during summer 2020 as well as reports on the negative impact of witnessing this brutality on the well-being of children (Bor

Shawn Jones and Riana Anderson share first authorship on this manuscript.

Shawn C. T. Jones

scjones4@vcu.edu

1 Virginia Commonwealth University, 800 W Franklin St., Richmond, VA 23223-2018, USA

2 University of Michigan, Ann Arbor, MI, USA

3 University of Pennsylvania, Philadelphia, PA, USA et al., 2018; Dastagir, 2020). As Black and Brown communities protested racial disparities in health, wealth, and justice systems illuminated by Floyd's public murder and the pandemic, a historical pattern re-emerged, a metaphorical rhythm of racism and its implications, as well as its denial. With just a cursory review of American history of Black and Brown people striving for civil rights, this predictable pattern emerged not only as repetitive but also embedded in the fabric of American life, thus begging an obvious question for Black and Brown families: "How do we raise our children in a society that has no regard for the life, liberty, or happiness of our children - yesterday, today, and tomorrow?".

Racial socialization is an important response to this complex and multifaceted question. Racial socialization, or the communication between family members about how to emotionally, intellectually, and behaviorally survive and transcend the daily trauma experiences of race and racism (Anderson \& Stevenson, 2019), has emerged as a protective factor in the psychosocial resilience of Black and Brown youth. Notably, the research literature surrounding racial socialization, like the development of any construct in resilience science, has sought to answer a series of implicitly stated interrogatives: 
- Why should families engage in racial socialization?

- What should families say regarding race and racism?

- When should families engage in racial socialization?

- How should families undertake the task of racial socialization?

The foregoing questions represent only a subset of those possible. In our observation, much of the racial socialization literature has focused on the content of this dialogue and asserts that parents provoke racial socialization. This content-centric perspective has been defined as The Talk both in scientific and lay discourse (Public Broadcasting Service, 2020). More recently, scholars have beseeched those of us doing work in this space to consider that if parents are tasked with providing racial socialization messages, then it is important that they feel as confident, skillful, and as minimally stressed as fighting against racism as can possibly be (Anderson et al., 2020). These scholars refer to the importance of parents' competency in racial socialization as Walking The Talk (see Jones et al., 2021). Although both The Talk and Walking The Talk serve as critical to understanding the resilience-building capacity of racial socialization, another important consideration remains. We have yet to understand how the dynamic of relational and symbiotic movement influences this protective process. Though racial socialization has been proposed as dyadic or bi-directional (Hughes et al., 2006; Smith-Bynum et al., 2016), its systemic dynamics and nature have been neglected, unlike how resilience is viewed through a systemic lens. Our goal in this paper is to redress the static notion of The Talk and build upon Walking The Talk by framing the systemic nature of racial socialization as The Dance. We endeavor to do this through an integration of various literatures, including family systems, resilience, and sociobiology, with recommendations toward methodological and applied practices to promote resilience and healing in the face of racial adversity and trauma.

\section{Background Music: Systemic Racism as the Persistently Arrhythmic Hiss}

Before considering racial socialization from the perspective of The Dance, it is critical to acknowledge the background music - the historical and contemporary realities of racism. First, we consider the rhythms of racism. If rhythm concerns the element of reoccurring movements and beats across time in music, then the rhythms of American racism have persisted across more than four centuries. These rhythms are invisible and audible as they repeat amid the irregular background hum of white supremacy evident in societal system policies and leadership decisions (Jones, 2000). These nefarious beats emerge as a recurring pattern of racial dehumanization for people of color in America. This pattern started with Indigenous genocide and displacement, then Black and Brown enslavement, followed by broken promises of hope and change from Reconstruction through Jim Crow segregation, and then morphed into decades of discrimination, stigmatization, and retrenchment in institutional policies and practices (Darity \& Mullen, 2020). Historically, American democracy has served as anything but the perfect metronome. Instead of marking tempo for justice, it has been "keeping the beat" of racial terror alive and the music has been discordant: for many Black and Brown families, the narrative of the so-called American dream has felt out-ofsync with their lived realities. The premature projection of racial progress and a post-racial society have seemed like a clanging cymbal when racial hate has been the more dominant backdrop. Indeed, one critical dimension of evaluating the psychological impact of racism has been the frequency with which such events occur. The syncopation of the racial rhythms that have plagued Black and Brown communities has historically been recorded by the spoken and written word and by still black and white photography that give the veneer of a bygone era. Recently, however, social media and personal cellular phone video recordings have allowed for the pulse of racism to be felt by the global public and in real time. How are Black families to respond to the amplified pace and decibels of racism threatening their youth, even if the overtness of it has modulated over time?

If the rhythms of racism concern the frequency of racism experienced individually and felt collectively over time, then the melody of racism concerns its varying themes. Just as melody relates to the notes played together, so too does the racism enacted upon Black and Brown individuals, families, and communities. These themes primarily play out across time in individual (the most often discussed elements of prejudice and discriminatory racial encounters) institutional (policies and practices that serves to restrict, oppress, or exploit), and cultural (racialized worldviews reflective of beliefs in racial differences that favor one group over another) ways (Jones, 1997). That said, scholars have identified multiple other expressions of racism, such as vicarious (such as repeatedly witnessing the aforementioned murder of Black and Brown bodies), internalized (accepting negative messages about one's racial group), and, relevant to the family context, intergenerational (when the rhythms and melodies of racism are passed down; Clark et al., 1999; Harrell, 2000; Jones, 2000) experiences.

Unfortunately, quite unlike the pleasing realities of rhythms and melodies often produced in a musical context, the rhythms and melodies of racism produce a harmful [dis] harmony when the combined elements of frequency, bother, and type of racism are considered. The implications of racism are deleterious for the lives of Black and other minoritized youth, as a number of systematic reviews have found (Hope et al., 2015; Priest et al., 2013; Williams 
$\&$ Mohammed, 2009). These reviews are joined by recent and ongoing empirical studies that indicate, for example, the increased depression (English et al, 2020), anxiety, and trauma (Tynes et al., 2020) that Black youth experience as they navigate multiple forms of racism. These "chords" feel anything but harmonious within communities of color, leaving Black parents befuddled on how to prepare their children to be and become healthy, wealthy, and wise amid this cacophony.

\section{Racial Socialization as The Talk: Putting Rhymes to the Beat of Racism}

Despite the immense overtones of its existence, getting the fields of psychology and human development to acknowledge racism as traumatic across the life course took centuries. The field of racial socialization started over four decades ago as a way to alert psychology of an unidentified coping strategy for families of color to combat the sting of racism (e.g., Bowman \& Howard, 1985; Spencer, 1983). Early attempts to study racial socialization as a science focused on establishing racial socialization as a viable construct where multiple definitions and measures were proposed. Targeting the content and frequency of what parents communicate to their children eventually expanded to measuring adolescent perceptions of their parents' content and frequency of racial socialization (Stevenson et al., 2002). In many ways, the racial socialization literature's response to the maniacal music of racism was to establish The Talk.

In service of this aim, early qualitative studies alerted us that many parents start to have this talk when their children are young (Peters, 1985; Spencer, 1983, 1990; Thornton et al., 1990). Quantitative measurement studies of attitudes, (Stevenson et al., 1997) and frequency (Hughes \& Chen, 1997) of racial socialization content followed and quickly populated the literature. Racial socialization content of family communications, or the key components of The Talk, included cultural pride, racism awareness, egalitarianism, preparation for bias, and cultural socialization (Hughes et al., 2006). Some scholars identified that who was giving the talk (source), to whom the talk was being given (gender), or other contextual factors surrounding racial socialization mattered in youth prosocial and psychosocial outcomes. The field grew as researchers found more positive and prosocial than neutral or negative associations from more frequent racial socialization, along with more associations to children's emotional, academic, and identity well-being outcomes in their studies of diverse Black and Brown families (Evans et al, 2012; Hughes et al., 2006; Huguley et al., 2019; Wang \& Huguley, 2012).

Racial socialization as The Talk represents a critical response to navigate the realities of racism. Notwithstanding these contributions, the field needed to contend with the truth that not all families have to parent with the nagging fear that racism can disrupt their child's past, present, and future. Moreover, it was necessary to acknowledge that the added burden for Black and Brown parents is far more complicated when one considers how they must parent knowing that America's racism rhythms are not temporary, but continual. With respect to the systemic racism that had been steadily thumping for the past $400+$ years, racial socialization scholars identified not just a present trauma in these conversations with families, but a redressing of the historical traumas waged against their families, communities, and culture (e.g., family separation and torture, imprisonment, public lynchings, police killings). While the PTSD literatures may have been useful in conceptualizing some of the more contemporary traumas, socialization scholars had to grasp how compounded and complex trauma (Jones, 1997) tied to historical events sounded a familiar tune in the discussions and actions waged by parents to keep their children not just safe, but alive. This acknowledgment brings with it a tension in this field: the assertion that racial socialization research should not simply elucidate but alleviate the fear and trepidation that Black and Brown parents experience when trying to keep their children protected.

\section{A "Step" in the Right Direction: Walking The Talk in Racial Socialization}

Not only do parents of Black and Brown children worry about their children being racially profiled (Anderson et al., 2021), they secretly fear their racial socialization strategies may not work. Given this worry, understanding family racial socialization based on parent-child communication content alone (i.e., The Talk) may be insufficient. Racial Encounter Coping, Appraisal, and Socialization Theory (RECAST; Anderson \& Stevenson, 2019; Stevenson, 2014) was designed to explain how The Talk could be an effective coping strategy employed by minoritized families to prepare for and protect against the negative truths and consequences of daily acts of racism they cannot avoid. While racism's rhythms and melodies are harmful to physical and emotional well-being (Williams et al., 2019), how well parents deliver racial socialization strategies to their children varies. That variability could mean some children are less prepared for the trauma effects when facing racism daily. Herein lies the new challenge of whether racial socialization, through intentional intervention efforts, can improve the chances, probability, and competence of racial socialization providers to prevent and alleviate the trauma, not only of the children, but the entire family. This approach centers the notion of competency in racial socialization, or the skills, stress, and confidence inherent in racial communication with 
children (Anderson et al., 2020). Raising children is a challenging task for anyone; however, unique socialization factors, including building confidence and skills, are needed to effectively equip Black and Brown children to succeed in a society plagued with racial strife.

For instance, Anderson et al. (2021) found that the more confident and competent Black parents are in providing racial socialization which in turn can reduce fear of their children being racially profiled, the less influence racial discrimination experiences have on their children's psychosocial problems. This work points to the importance not just of racial discrimination and dehumanization as key to understanding racial trauma, but what Black and Brown families and youth can $d o$ to mitigate and heal from the negative impact of that trauma on behavioral, health, and relationship outcomes. Furthermore, as this study illuminates, the research on racial socialization competency is meant to put The Walk in The Talk by realizing that not just children but parents need racial protection and affirmation and that racial socialization competency buffers parental and youth stress and psychological symptoms (Anderson et al., 2021). Expecting parents to give The Talk without managing their racial trauma histories is problematic and myopic once the influence of systemic processes is taken into account. Walking The Talk is about how parents can become more skilled at emotionally regulating their racial trauma so they can be more competent in preparing their children to manage and transcend racial hate, thriving in spite of the proverbial background music of racism.

\section{Inviting the Dance: Using Family Systems to Enrich Racial Socialization}

By proposing the utility of integrating family systems thinking into the field of racial socialization theory, measurement, and intervention, we intend to address the discordant rhythms, unpleasant melodies, and hateful disharmonies of racism that families must face. In family systems theory, families are thought to abide by a set of behavioral, emotional, and interactional norms (Rambo \& Hibel, 2013). Furthermore, a goal within families is to maintain homeostasis, or stability, both for the health of the family and its individual members. When events inevitably arise which threaten that system's balance, the system finds ways to correct the imbalance. Imbalances can happen within the system naturally (e.g., the birth of a baby or success of a business) or from outside the system (e.g., the steady beat of racism). These imbalances create stress that can incapacitate and/or strengthen the systems' problem-solving abilities (Rambo \& Hibel, 2013).

Importantly, the self-correction of families to stressors is a task that is conceptualized not as static, but rather, dynamic, with the family system thought to be constantly in flux. Indeed, a number of family system theorists and therapists have referred to this dynamic flux as a family dance. Just as a systems approach to thinking about psychological functioning moves beyond an overemphasis on an individual's role and responsibility, so too does a shift from racial socialization as The Talk to The Dance. This shift liberates the field from an overemphasis on the parent's messages, without consideration of how the family collectively responds to the rhythms of racism to maintain an optimal homeostasis.

To be fair, The Talk does contain elements of dance, just as the research centered on content and frequency consistently alluded to the importance of bi-directional and synergistic elements (Hughes et al., 2006). However, dance from the perspective of The Talk is more analogous to a line dance, in which rote movements and directions are provided by the leader and everyone else is supposed to follow. While youth may be instructed to and indeed "do the right things" when encountering racism, including putting their hands on "10 and 2" (an informal saying depicting the placement of hands on a steering wheel like the hands of a clock during police stoppages), or pulling their hoodie down when walking into a store, they are without freedom to express their own style, resistance, or understanding as to why these coping approaches are necessary.

The theoretical suppositions of racial socialization competency are inherently more bi-directional than a static version of racial socialization. Nevertheless, a sole focus on parental competency, which defines Walking The Talk, situates parents again as dance instructor, only this time they are supported and encouraged in watching themselves dance in the mirror before they provide lessons to their youth. The hope is that this self-monitoring improves the "form" and that, in turn, youth will also be better positioned to "catch the beat" and make the necessary movements for survival. If we instead encourage racial socialization competency to be viewed as a tango (a South American-originated partnered dance), we have a wealth of similarities from which to draw.

The mechanism behind the tango's classic abrazo (embrace) "is not rigid, but flexibly adjusts to different steps, and may vary from being quite close ... to open. [While] experienced dancers frequently dance in closed position... it may be better for beginners...to use a more open position." ("Tango," 2021). This acknowledgment of the competency spanning from beginners to experienced indicates that varying strategies may need to be used for varying levels of proficiency within the partners (or family in the case of racial socialization). Recently, the tango has seen a change in who "leads" the dance, reflecting a shift in gender norms (Davis, 2015). Although racial socialization competency is not squarely focused on gender roles, the social norm shift of the tango can easily help us to understand the importance 
of viewing parent-child roles as malleable, reciprocal, and responsive to feedback. In particular, we note how children contribute to their own racial learnings and equally influence caregivers of new styles, content, or concerns. Who leads the socialization, thus, can switch in the middle of the dance.

Returning to the notion of homeostasis, inviting the dance allows us to understand how negative and positive feedbacks occur in the context of racial socialization to create feedback loops. Briefly, negative feedback occurs when the system is outside of acceptable homeostasis and serves to get back to "more of the same" (Bateson, 1972; Watzlawick et al., 2011). When the hum of White supremacy crescendos or the rhythms of racism become an immediate threat, a child may share with their parent(s) a discriminatory racial encounter, an attempt at dehumanization. The dance metaphor allows us to understand this sharing of the child can both trigger past parental trauma and yet present parental opportunity to help reduce the child's trauma. The parental feedback may involve a well-timed message ("You have to work twice as hard," "Your complexion is beautiful despite what people say," "God's got us") to rebalance the child and family back to a sense of normal humanization. Even parents who choose silence do so hoping for a return to "normalcy." While these messages may work at times, observing the family dance of racial socialization may reveal when they do not. As in family systems theory, to see the dance is a meta-advantage that offers parents and children choices, rather than reactions. Racial socialization competency is proposed as a meta-advantage that self-corrects, which serves as a positive feedback loop of sorts, deepening the efficacy of those socialization messages, and potentially bringing the family to a new, healthier "normal." In this way, seeing how the family dances can illuminate their reactions to racial dehumanization as patterns that maintain and/or disrupt the traumatic impact of racism. The messages communicated, the stances taken, and the coping strategies enacted all serve as the "dance moves" to the background music of racism. The meta-advantage for parents and children is in seeing this dance happen while it is happening and choosing whether these moves are useful or not.

In addition to homeostasis and feedback, one final way a family systems perspective and The Dance advances our understanding of racial socialization is in attending to the communication. Indeed, family systems theories offer a simple assertion: "one cannot not communicate" (Watzlawick et al., 2011, p.57), which is meant to indicate that all behavior is a form of communication. This reframe, along with the complementary notion of metacommunication, or the messages behind the message, is immensely helpful for advancing our understanding of racial socialization. Quite simply, it acknowledges what every dancer knows: communication is verbal and nonverbal. Watching a couple intertwined in the dance of the tango, we can appreciate this reality. So too, seeing the metacommunication of the family dance of racial socialization will undoubtedly reveal the importance of non-verbal messages, behaviors, actions, and advocacy. How mom reacts to son's story matters and daughter's eyeroll following father's messages preparing her for bias matters as well. In the same way, teens feel compelled to "resist" or "trust but verify" parental racial socialization, and parents may feel equally compelled to "deliver the truth, no matter where it lands."

\section{Taking Part in The Dance}

To capture the dance of racial socialization dynamics, our research methods must evolve in ways that push us to focus beyond the content of the communication. In addition, it is important that we not only capture the dance in our measurement, but also invite The Dance. By observing and providing feedback to families as they enact and practice the realities of responding to racism in real time, intervention efforts can be more efficacious in noticing the meta elements of family communication, emotional support, and practice for racial conflicts. This dynamic approach of seeing how racism works through racial encounters to dehumanize can encourage youth to develop greater racial coping selfefficacy, and instead of avoid, successfully engage a stressful racial encounter (Anderson \& Stevenson, 2019). Racial coping self-efficacy allows Black youth to perceive more emotional and behavioral coping tools to employ when faced with a racially discriminatory event (e.g., Schwarzer \& Renner, 2000), and bolsters youth's assertive and empowering racial coping strategies. In turn, if youth develop multiple and agentic racial coping strategies - cultivated from racial socialization and strengthened by racial coping self-efficacy - perhaps they will become more efficient in resolving racially stressful matters and absolve negative psychosocial outcomes. We discuss both methodological and applied extensions of this work in the subsequent sections.

\section{Capturing and Observing The Dance}

One critical way to capture components of the family dance in racial socialization is via dyadic data analyses. In particular, there have been recent investigations of racial socialization that use actor-partner interdependence modeling (APIM; Kenny et al., 2006). APIM allows a researcher to assess effects at the level of the dyad, as well as the role that both one's own scores (actor effect) and another's (partner effect) has on outcomes of interest (Kenny \& Ledermann, 2010). In this way, we are able to model how a parent or child's worry influences the racial socialization of the other. It is possible greater racial coping self-efficacy might not 
only affect racial healing, but that benefit could spill over to other family members. Empirical examples of this approach are growing in the racial socialization literature and have also brought attention to the dance that exists between parents in Black families (Jones \& Neblett, 2019; McNeil Smith et al., 2016).

In addition to the use of dyadic and interdependence modeling to capture aspects of the dance, observing the family dance is also important. Such approaches have been employed in a small quantity of studies of racial socialization (Coard \& Wallace, 2001; Johnson, 2005; Lewis, 1999; Smith-Bynum et al., 2016). Lewis' (1999) combined aspects of attachment theory to develop a naturalistic observation procedure of mother-child discussions during hair combing. The Parent-Child Race-Related Observational Measure (PC-ROM; Coard \& Wallace, 2001) examines interactions between Black parents and young children). Johnson (2005) assessed how parent-child dyads navigated several openended scenarios centered on dealing with racial conflict the Racial Stories Task (RST). Smith Bynum and colleagues (2016) expanded several of the aforementioned approaches and utilized a vignette-based task to observe conversations between Black mothers and adolescents. Each of these studies provides some insight into the family dynamic or dance, and the legacy of observational approaches is deeply associated with family systems approaches (McHale, 2011).

\section{EMBRacing The Dance}

Drawing from RECAST and with a specific desire to capture, observe, and improve family dance skills, the Engaging, Managing, and Bonding through Race (EMBRace) program (Anderson et al., 2018a, 2018b, 2019b) provides an applied component to earlier observational studies. EMBRace is a novel racial socialization intervention for parents, children, and clinicians with several goals. Namely, the program aspires to dynamically improve parents' racial socialization competence, Black youth's confidence and strategies to effectively cope with racial stress, and clinicians' ability to serve Black clients for culturally relevant stressors. The goal of EMBRace is not to specify what parents and facilitators should say (i.e., content), but rather how to deliver racial socialization (i.e., competence) and apply it (e.g., behaviors) to discriminatory racial encounters. As such, the racial socialization content that parents already or hope to discuss with their child is used as material in the session along with psychoeducation to help facilitate dialogue. In addition to participants' personal experiences, EMBRace utilizes common racial experiences (e.g., getting pulled over) throughout the intervention to bolster ecological validity and healing of racial traumas. Specific strategies to address racial trauma include affirmation and acknowledgment, validation, naming racial oppression, externalizing and counteracting devaluation, and rechanneling rage. EMBRace consists of five weekly sessions per family (each $90 \mathrm{~min}$ ). Sessions are segmented into three components: separate, concurrent sessions for caregivers and youth (30 min); a break (15 min); and conjoint sessions during which family dyads and clinicians review, discuss, and practice the skills they learned in their separate sessions (45 $\mathrm{min})$. The latter sessions are critical to inviting the family dance.

Although several publications detail the development and prior findings of EMBRace (Anderson et al., 2018a, $2018 b, 2019 b$ ), recent quotes from the deployment of the intervention during COVID-19 and the racial uprisings of 2020 provide insight into how families have learned to listen to and observe one another and their clinician and to integrate new practices and ideas to respond to the rhythms of racism. For example, a White adoptive mother noted that while she was aware of Black history and culture, she had a hard time connecting with her Black children around race and needed help with these new moves to engage in the dance with her children. "It's kind of an interesting place to try and nurture that [racial socialization] when I'm not from that group," she stated. "I started asking [my Black daughter], what would be helpful for you? What would be important for you?" She continued, "my preference would be to talk about [race] from a philosophical point of view and constructionist point of view. But [my children are] going to have experiences, and society has a lot of input on that."

Additionally, a Black child explained how important discussing racial conversations are with her family: "We think it's really important that we should talk more about situations, racial and otherwise. If we have some type of situation that's not good or stressful, we should talk about it, so we can better communicate about it, so you know, if one person isn't feeling well or doing well, talking to each other will help us more." These cognitive concepts help children to consider what to do behaviorally as well. Take for instance the advancement of thought and action in this child: "I would say these [EMBRace sessions] are helpful. Because I'm being asked questions I don't normally get asked. It's forcing me to think about these things, and I think I know what I will do if I get racially profiled and who I'll talk to." Finally, in the same way the dance requires thought, movement, and touch, we see how physical actions accompany improving racial dialogue between family members. "So um, sometimes, when we talk about hard conversations, I'll give her a hug sometimes. If she's sitting at the table, I'll come sit next to her and listen. Communication wise, I want to listen," noted another child. These and other findings suggest that applied programs working with families to engage in the dance of racial socialization are necessary and welcomed. 


\section{"Moving" Beyond Resilience: How Does The Dance Afford Black Youth Resistance?}

When caregivers, providers, and youth actively engage the dance via cognitive, emotional, and behavioral strategies to redress racism, children are less likely to be burdened by oppression. They are able to read the dance floor, recast the beats and rhymes of racism, and resolve racially stressful moments in ways that prioritize their humanity. Resilience, by definition, refers to one's ability to bounce back in the face of adversity (Luthar et al., 2015; Ungar, 2008). Often seen as an individual characteristic, resilience is like a rubber band, in which the entire purpose of the elastic is to stretch and return to normal. Indeed, adaptability is its core characteristic. But when rubber bands are negatively impacted by their environment, such as sitting by the window and getting weathered by the sun or becoming fragile if it has been in a cold space, it may snap. Or even without weathering, it may snap because it is overused beyond its capacity. Should we rely on our children to be the ones to "bounce" back, or should we be preventing them from having to stretch in the first place? Extending this analogy to our discussion of the dance and the family systems notions of homeostasis, should our instruction to Black and Brown youth and families be to dance to exhaustion in an attempt to battle racism that is unhealthy with which to begin?

Unlike resilience, resistance asks what we can do in ourselves, families, and greater community to both avoid environmental weathering and likely exhaustion from constant use. The resistance that we have toward these systems impacting our child is akin to The Dance that we engage in that takes the onus off of our child to be individually resilient. For example, what would our school look like if we were resistant to racial oppression and racial injustice? If we do not pause to acknowledge the challenges facing youth within their environment when they come into the school, we are complicit with allowing the system of racial oppression to continue to harm them within the school. Acknowledging, "Wow, Trayvon looks a lot like the kids in this classroom. Gee, Tamir was the same age as the kids in this class," allows us as adults to read, recast, resolve, and eventually resist how that system is negatively impacting our children. Racial socialization as a dance allows us not only to practice some of the challenging moves with our children but also allows us to think critically about our role in the development and external factors leading to new and improved moves. We are not denying the impact of historical trauma on our families, rather, incorporating strategies across generations and with our children to combat such impact. However, if we acquiesce to the status quo and allow our children to be bombarded and consumed by the racist rhythms, melodies, and disharmony the world is currently throwing at them, we are depending on them to be resilient, when it is up to us to be resistant.

In summary, we propose that seeing racial socialization through the lens of systemic processes expands The Talk into a family dance that promotes awareness of the dance floor climate, not just one's own abilities; encourages disruption of systemic interruptions to this dance, such as inequitable turntables or resources requiring the dance; and brings greater attention to the discordant rhythm and beats of White supremacy in the background behind the policies and practices of societal institutions. Families engaging in this process-oriented and dyadic display of syncopation will be more prepared to disrupt the discordance together.

Availability of Data and Material Not applicable.

Code Availability Not applicable.

\section{Declarations}

Ethics Approval Not applicable.

Consent to Participate Not applicable.

Consent for Publication Not applicable.

Conflict of Interest The authors declare no competing interests.

\section{References}

Anderson, R. E., \& Stevenson, H. C. (2019). RECASTing racial stress and trauma: Theorizing the healing potential of racial socialization in families. American Psychologist, 74(1), 63-75. https://doi. org/10.1037/amp0000392.

Anderson, R. E., Jones, S. C. T., Navarro, C. C., McKenny, M. C., Mehta, T. J., \& Stevenson, H. C. (2018a). Addressing the mental health needs of Black American youth and families: A case study from the EMBRace intervention. International Journal of Environmental Research and Public Health, 15(5). https://doi.org/10. 3390/ijerph15050898.

Anderson, R. E., McKenny, M., Mitchell, A., Koku, L., \& Stevenson, H. C. (2018b). EMBRacing racial stress and trauma: Preliminary feasibility and coping responses of a racial socialization intervention. Journal of Black Psychology, 44(1), 25-46. https://doi.org/ 10.1177/0095798417732930.

Anderson, R. E., Jones, S. C. T., Anyiwo, N., McKenny, M., \& Gaylord-Harden, N. (2019a). What's race got to do with it? Racial socialization's contribution to Black adolescent coping. Journal of Research on Adolescence, 29, 822-831. https://doi.org/10.1111/ jora. 12440.

Anderson, R. E., McKenny, M. C., \& Stevenson, H. C. (2019b). EMBRace: Developing a racial socialization intervention to reduce racial stress and enhance racial coping among Black parents and adolescents. Family Process, 58(1), 53-67.

Anderson, R. E., Jones, S. C. T., \& Stevenson, H. C. (2020). The initial development and validation of the Racial Socialization Competency Scale: Quality and quantity. Cultural Diversity and Ethnic Minority Psychology, 26(4), 426-436. https://doi.org/10.1037/ cdp0000316. 
Anderson, R. E., Jones, S. C. T., Saleem, F. T., Metzger, I., Anyiwo, N., Nisbeth, K. S., Bess, K. D., Resnicow, K., \& Stevenson, H. C. (2021). Interrupting the pathway from discrimination to Black adolescents' psychosocial outcomes: The contribution of parental racial worries and racial socialization competency. Child Development. https://srcd.onlinelibrary.wiley.com/doi/abs/10.1111/cdev. 13607.

Bateson, G. (1972). Steps to an ecology of mind. University of Chicago Press.

Bor, J., Venkataramani, A. S., Williams, D. R., \& Tsai, A. C. (2018). Police killings and their spillover effects on the mental health of black Americans: A population-based, quasi-experimental study. The Lancet, 392(10144), 302-310. https://doi.org/10.1016/S01406736(18)31130-9.

Bowman, P. J., \& Howard, C. (1985). Race-related socialization, motivation, and academic achievement: A study of Black youths in three-generation families. Journal of the American Academy of Child Psychiatry, 24(2), 134-141.

Clark, R., Anderson, N. B., Clark, V. R., \& Williams, D. R. (1999). Racism as a stressor for African Americans: A biopsychosocial model. American Psychologist, 54(10), 805.

Coard, S. I., \& Wallace, S. A. (2001). The parent-child race-related observational measure (PC-ROM): Unpublished manual. Department of Human Development and Family Studies, University of North Carolina-Greensboro.

Darity W. A. Jr, \& Mullen, A. K. (2020). From here to equality: Reparations for Black Americans in the twenty-first century. UNC Press Books.

Dastagir, A. E. (2020). The pandemic is taking a toll on Americans' mental health. A new CDC study shows who we need to worry about most. USA Today. Retrieved from https://www.usatoday. com/story/news/health/2020/08/13/covid-19-takes-mental-tollyouth-minorities-essential-workers/3365719001/.

Davis, K. E., Sociology, \& Identities, Diversity and Inclusion (IDI). (2015). Dancing tango: Passionate encounters in a globalizing world. New York University Press. https://research.vu.nl/en/publi cations/9d1b768d-8361-4edb-970b-19316dbf2966.

English, D., Lambert, S. F., Tynes, B. M., Bowleg, L., Zea, M. C., \& Howard, L. C. (2020). Daily multidimensional racial discrimination among Black U.S. American adolescents. Journal of Applied Developmental Psychology, 66, 101068. https://doi.org/10.1016/j. appdev.2019.101068.

Evans, A. B., Banerjee, M., Meyer, R., Aldana, A., Foust, M., \& Rowley, S. (2012). Racial socialization as a mechanism for positive development among African American youth. Child Development Perspectives, 6(3), 251-257. https://doi.org/10.1111/j.1750-8606. 2011.00226.x.

Harrell, S. P. (2000). A multidimensional conceptualization of racismrelated stress: Implications for the well-being of people of color. American Journal of Orthopsychiatry, 70(1), 42-57.

Hope, E. C., Hoggard, L. S., \& Thomas, A. (2015). Emerging into adulthood in the face of racial discrimination: Physiological, psychological, and sociopolitical consequences for African American youth. Translational Issues in Psychological Science, 1(4), 342-351. https://doi.org/10.1037/tps0000041.

Hughes, D., \& Chen, L. (1997). When and what parents tell children about race: An examination of race-related socialization among African American families. Applied Developmental Science, 1(4), 200-214. https://doi.org/10.1207/s1532480xads0104_4.

Hughes, D., Rodriguez, J., Smith, E. P., Johnson, D. J., Author, H. C., \& Spicer, P. (2006). Parents' ethnic-racial socialization practices: A review of research and directions for future study. Developmental Psychology, 42, 747-770. https://doi.org/10.1037/0012-1649. 42.5.747.
Huguley, J. P., Wang, M.-T., Vasquez, A. C., \& Guo, J. (2019). Parental ethnic-racial socialization practices and the construction of children of color's ethnic-racial identity: A research synthesis and meta-analysis. Psychological Bulletin, 145(5), 437-458. https:// doi.org/10.1037/bul0000187.

Johnson, D. J. (2005). The ecology of children's racial coping: Family, school, and community influences. In T. S. Weisner (Ed.), Discovering successful pathways in children's development: Mixed methods in the study of childhood and family life (pp. 87-109). University of Chicago Press.

Jones, J. M. (1997). Prejudice and racism. McGraw-Hill Humanities, Social Sciences \& World Languages.

Jones, C. P. (2000). Levels of racism: A theoretic framework and a gardener's tale. American Journal of Public Health, 90(8), 12121215. https://doi.org/10.2105/ajph.90.8.1212.

Jones, S. C. T., \& Neblett, E. W. (2019). Black parenting couples' discussions of the racial socialization process: Occurrence and effectiveness. Journal of Child and Family Studies, 28(1), 218-232. https://doi.org/10.1007/s10826-018-1248-4.

Jones, S. C. T., Anderson, R. E., \& Stevenson, H. (2021). Differentiating competency from content: Racial socialization profiles and their associated factors.

Kenny, D. A., \& Ledermann, T. (2010). Detecting, measuring, and testing dyadic patterns in the actor-partner interdependence model. Journal of Family Psychology, 24(3), 359-366. https://doi.org/ 10.1037/a0019651.

Kenny, D. A., Kashy, D. A., \& Cook, W. L. (2006). Dyadic data analysis. Guilford Publications.

Lewis, M. L. (1999). Hair combing interactions: A new paradigm for research with African-American mothers. American Journal of Orthopsychiatry, 69(4), 504-514. https://doi.org/10.1037/h0080 398.

Luthar, S. S., Grossman, E. J., \& Small, P. J. (2015). Resilience and adversity. In Handbook of child psychology and developmental science: Socioemotional processes, Vol. 3, 7th ed (pp. 247-286). Wiley. https://doi.org/10.1002/9781118963418.childpsy307.

McHale, J. P. (2011). Assessing coparenting. In J. P. McHale, J. P. McHale, K. M. Lindahl (Eds.), Coparenting: A conceptual and clinical examination of family systems (pp. 149-170). American Psychological Association. https://doi.org/10.1037/12328-007.

McNeil Smith, S., Reynolds, J. E., Fincham, F. D., \& Beach, S. R. H. (2016). Parental experiences of racial discrimination and youth racial socialization in two-parent African American families. Cultural Diversity and Ethnic Minority Psychology, 22(2), 268-276. https://doi.org/10.1037/cdp0000064.

Peters, M. F. (1985). Racial socialization of young Black children. In Black children: Social, educational, and parental environments. (pp. 159-173). Sage Publications, Inc.

Priest, N., Paradies, Y., Trenerry, B., Truong, M., Karlsen, S., \& Kelly, Y. (2013). A systematic review of studies examining the relationship between reported racism and health and wellbeing for children and young people. Social Determinants of Child Health, 95, 115-127. https://doi.org/10.1016/j.socscimed.2012.11.031.

Public Broadcasting Service. (2020). The Talk: Race in America. https://www.pbs.org/show/talk-race-america/.

Rambo, A., \& Hibel, J. (2013). What is family therapy? Underlying premises. In A. Rambo, C. West, A. Schooley, \& T. V. Boyd (Eds.), Family therapy review: Contrasting contemporary models (pp. 3-8). Routledge/Taylor \& Francis Group.

Schwarzer, R., \& Renner, B. (2000). Social-cognitive predictors of health behavior: Action self-efficacy and coping self-efficacy. Health Psychology, 19(5), 487-495. https://doi.org/10.1037/ 0278-6133.19.5.487.

Smith-Bynum, M. A., Anderson, R. E., Davis, B. L., Franco, M. G., \& English, D. (2016). Observed racial socialization and maternal 
positive emotions in African American mother-adolescent discussions about racial discrimination. Child Development, 87(6), 1926-1939. https://doi.org/10.1111/cdev.12562.

Spencer, M. B. (1983). Children's cultural values and parental child rearing strategies. Developmental Review, 3(4), 351-370.

Spencer, M. B. (1990). Parental values transmission: Implications for Black child development. In J. B. Stewart \& H. Cheatham (Eds.), Interdisciplinary perspectives on Black families (pp. 111-130). New Brunswick, NJ: Transactions.

Stevenson, H. (2014). Promoting racial literacy in schools: Differences that make a difference. Teachers College Press.

Stevenson, H. C., Reed, J., Bodison, P., \& Bishop, A. (1997). Racism stress management: Racial socialization beliefs and the experience of depression and anger in African American youth. Youth \& Society, 29(2), 197-222. https://doi.org/10.1177/0044118X97 029002003.

Stevenson, H. C., Cameron, R., Herrero-Taylor, T., \& Davis, G. Y. (2002). Development of the teenager experience of racial socialization scale: Correlates of race-related socialization frequency from the perspective of Black youth. Journal of Black Psychology, 28(2), 84-106. https://doi.org/10.1177/0095798402028002002.

Tango. (2021). In Wikipedia. https://en.wikipedia.org/w/index.php? title $=$ Tango\&oldid $=1025144558$.

Thornton, M. C., Chatters, L. M., Taylor, R. J., \& Allen, W. R. (1990). Sociodemographic and environmental correlates of racial socialization by Black parents. Child Development, 61(2), 401-409.

Tynes, B. M., English, D., Del Toro, J., Smith, N. A., Lozada, F. T., \& Williams, D. R. (2020). Trajectories of online racial discrimination and psychological functioning among African American and Latino adolescents. Child development, 91(5), 1577-1593.

Ungar, M. (2008). Resilience across cultures. The British Journal of Social Work, 38(2), 218-235. https://doi.org/10.1093/bjsw/ bcl343.

Wang, M.-T., \& Huguley, J. P. (2012). Parental racial socialization as a moderator of the effects of racial discrimination on educational success among African American adolescents. Child Development, 83(5), 1716-1731. https://doi.org/10.1111/j.1467-8624. 2012.01808.x.

Watzlawick, P., Bavelas, J. B., \& Jackson, D. D. (2011). Pragmatics of human communication: A study of interactional patterns, pathologies and paradoxes. WW Norton \& Company.

Williams, D. R., \& Mohammed, S. A. (2009). Discrimination and racial disparities in health: Evidence and needed research. Journal of Behavioral Medicine, 32(1), 20-47. https://doi.org/10.1007/ s10865-008-9185-0.

Williams, D. R., Lawrence, J. A., \& Davis, B. A. (2019). Racism and health: Evidence and needed research. Annual Review of Public Health, 40(1), 105-125. https://doi.org/10.1146/annurev-publh ealth-040218-043750. 